International Journal of Engineering \& Technology, 7 (3.27) (2018) $415-420$
International Journal of Engineering \& Technology
SPC
Website: www.sciencepubco.com/index.php/IJET
Research paper

\title{
Study of Hardware Implementation on Size of the Microcalcification Detection Using Embedded Systems
}

\author{
G.R. Jothilakshmi ${ }^{*}$, P. Mohana Priya ${ }^{2}$, V.K. Suvithra ${ }^{3}$ \\ ${ }^{I}$ Assistant Professor, Department of ECE, VISTAS, Pallvaram, Chennai. \\ ${ }^{2} U G$ Scholar, Department of ECE, VISTAS, Pallvaram, Chennai. \\ ${ }^{3} U G$ Scholar, Department of ECE, VISTAS, Pallvaram, Chennai. \\ *Corresponding author E-mail:jothi.se@velsuniv.ac.in
}

\begin{abstract}
Detection of microcalcification in glandular breasts is highly critical for early stage cancer detection since, it is very small in size. To detect such smaller microcalcification a hardware device is needed, which is created by the using the digital mammography image from DDSM database the image of malignant breast is acquainted. Two levels of binning is carried out with respect to the RoI to calculate the range of reflection coefficient. Linear mapping of reflection coefficient with mass density is projected as $3 \mathrm{D}$ and simultaneously the size of respective second bin is calculated to derive the size if the microcalcification. This process is then implemented on hardware to make it more commercial for the people to detect the cancer at an early stage.
\end{abstract}

Keywords: Microcalcification, binning of image, reflection coefficient, mass density, intensity, mammogram image.

\section{Introduction}

Breast cancer in women is the most common nowadays and very dangerous too. According to a survey review that $25 \%$ of women need aid on breast tumors because about $20 \%$ of women have been diagnosed with bosom(breast) cancer. It might be the heading purpose behind passing in light of cancer in women. The peril of bosom tumor can be diminished by having youngsters before 30, bosom encouraging, restricting liquor admission, keeping up a solid weight, practicing consistently. Chest tumor in women is the most surely understood nowadays and amazingly dangerous also. As demonstrated by statistical diagram around $25 \%$ of all illnesses examined in women are chest tumors and around $20 \%$ of each dangerous threat are chest developments. It is the main source of death because of malignancy in ladies. The danger of bosom growth can be decreased by having youngsters before 30, bosom bolstering, constraining liquor consumption, keeping up a solid weight, practicing consistently. As per Globocan 2012, India alongside United States and China by and large records for very nearly $33 \%$ of the worldwide bosom disease load. India is confronting testing circumstance because of $11.54 \%$ increments in frequency and $13.82 \%$ expansion in mortality because of bosom growth amid 2008- 2012.The primary explanations behind this watched climb in mortality is because of absence of deficient bosom tumor screening, conclusion of malady at cutting edge stage and inaccessibility of fitting medicinal offices. Bosom malignancy accomplishes top rank even in solitary registries (Mumbai, Bangalore, Chennai, New Delhi and Dibrugarh) in females in the midst of the season of 2012-2014 (Table 1). The relative degree of chest threat in different registries moved from $30.7 \%$ in Chennai to $19 \%$ in Dibrugarh (Table 1) Increasing urbanization and westernization related with changing lifestyle and support inclinations has lead chest tumor to accomplish top position in all major urban registries, while in
Barshi rural registry still cervical development is at top position in females and malady of chest holds second position. Chest tumor unpleasant rate (CR) among different registries showed most imperative rate in Thiruvananthapuram 43.9 (per 100 000) trailed by Chennai (40.6), New Delhi (34.8) and Mumbai (33.6). Among all the PBCR's fundamental four spots were controlled by Delhi with AAR 41.0 (per 100,000), Chennai 37.9, Bangalore 34.4 and Thiruvananthapuram District 33.7. A total zone clever minimum age adjusted recurrence rate per 100000 for India is showed up in Fig. S2. AAR more than 20 for every 100000 has been represented locales Chandigarh (39.5), Panchkula (34.6), Aizawl (36.2) and Goa (36.8).Bosom cancer is delegated mass and macrocalcification. Microcalcification is thought to be most defenseless nearly .A considerable measure of research are carried on in light of bosom growth, however inferring the span of microcalcification by building technique has not been examined. In this paper research and strategies in light of designing procedure is talked about. Breast cancer is classified as mass and microcalcificaation. Microcalcification is considered to be most vulnerable comparatively. A lot of research are carried on based on breast cancer, but deriving the size of microcalcification by engineering methodology has not been discussed. In this paper research and procedures based on engineering methodology is discussed.

\begin{tabular}{|l|c|c|c|c|}
\hline Breast & $\%^{\dagger}$ & $R^{\ddagger}$ & $\mathrm{CR}^{5}$ per 100000 & AAR $^{\Phi}$ per 100000 \\
\hline Mumbai & 28.8 & 1 & 33.6 & 33.6 \\
\hline Bangalore & 27.5 & 1 & 29.3 & 34.4 \\
Chennai & 30.7 & 1 & 40.6 & 37.9 \\
Thiruvanananthapuram & 28.5 & 1 & 43.9 & 33.7 \\
Dibrugarh & 19 & 1 & 12.7 & 13.9 \\
New Delhi & 28.6 & 1 & 34.8 & 41 \\
\hline Barshi Rural & 20 & 2 & 13.2 & 12.4 \\
\hline
\end{tabular}




\section{Microcalcifications}

Breast tumor is little calcium stores that create in a lady's bosom tissue. They are extremely normal and are generally favorable (noncancerous). In a few examples, certain kinds of bosom calcifications may propose early bosom malignancy. There are two sorts of bosom calcifications: macrocalcifications and microcalcifications. Macrocalcifications look like substantial white specks on a mammography (bosom X-beam) and are regularly scattered haphazardly inside the bosom. Macrocalcifications are common-they are found in approximately half of women over age 50, and one in 10 women under age 50 is considered cancerous. The term microcalcification alludes to calcifications of whom distance across is substandard compared to $1 \mathrm{~mm}$, realizing that present spatial determination mammography make little questions be identified without amplification for a size went in the vicinity of 100 and $200 \mu \mathrm{m}$. Recognition is, on a basic level, in light of the pictures acquired with an amplification of 1 , on establishments consenting to the predominant quality control models. The microcalcification is formed by deposition of calcium radicals like calcium oxalate, calcium phosphate. Benign Calcifications are composed of calcium oxalate whereas malignant calcifications are composed of calcium phosphate. The mass density of calcium oxalate is $2.12 \mathrm{~g} / \mathrm{cm}^{3}$ and calcium phosphate is $3.14 \mathrm{~g} / \mathrm{cm}^{3}$.

\section{Literature Survey}

The implemented method in the paper requires a mammography image which is quite complex, considering the recent inventions of many scanning and x-ray techniques such as CT scan and MRI.
The complexity of using a mammography image it is also very reliable to detect the microcalcification, since it is found either in small clusters or scattered particles the mammography image is more likely considerable. In this paper the importance of using a mammography image is rectified.

Depth segmentation method for cancer detection in mammography image ${ }^{1}$. For a highly dense breast an utilization of lucid centering for time inversion (TR) microwave imaging in shaft space for location and limitation of numerous tumor in exceptionally thick 3D bosom phantom. The physical characteristics is very important to detect microcalcification, thus we are using reflection coefficient as our physical characteristics it helps us to identify the nature of the particular crystal. Identification of microcalcification through its physical characteristics using mammogram image ${ }^{2}$. Here, split and merge technique is discussed which is one of the technique which is used in separating the region of abnormality. Mammogram division utilizing locale based strategies with spilt and combine strategy ${ }^{3}$.Design and FPGA implementation of contrast enhancement on mammogram images for early detection of breast cancer ${ }^{16}$. To discuss the basic methods that are involved in the detection of breast cancer, goes with, 3D plotting, sonogram, mammogram, CT scans etc. Comparative study on methods used for detection of breast cancer ${ }^{17}$. By applying image processing threshold and edge based on water shed segmentation. Breast cancer mass detection in mammogram using K-means and fuzzy $\mathrm{C}$ means ${ }^{18}$. These are the techniques and subjects that are available based on the detection of these are the techniques and subjects that are available based on the detection of microcalcification or breast cancer. After the study of various researchers on micro calcification we have learned that detection of micro calcification is quite hard compared to the tumor.

Table 1: Detailed Literature Survey on Breast Cancer with Microcalcifications

\begin{tabular}{|c|c|c|c|}
\hline S.no & Title & Author and journal & Technique and findings \\
\hline 1 & $\begin{array}{l}\text { Cancer detection in highly } \\
\text { dense breast using coherent } \\
\text { focused time-reversal } \\
\text { microwave imaging. }\end{array}$ & $\begin{array}{l}\text { Md. Delwar hossain, } \\
\text { IEEE Journal }\end{array}$ & $\begin{array}{l}\text { For a highly dense breast an exceptionally thick bosom a use of intelligent centering } \\
\text { for time inversion (TR) microwave imaging in shaft space for recognition and } \\
\text { restriction of different tumor in very dense 3D bosom ghost. }\end{array}$ \\
\hline 2 & $\begin{array}{l}\text { Extracting region of interest } \\
\text { using distinct block processing } \\
\text { methods in sonogram. }\end{array}$ & $\begin{array}{l}\text { G.R.Jothilakshmi } \\
\text { IEEE Journal }\end{array}$ & RoI from a sonogram is screened by using 3D plot binning. \\
\hline 3 & $\begin{array}{l}\text { Breast cancer mass detection in } \\
\text { mammogram using K-means } \\
\text { and fuzzy } \mathrm{C} \text { means. }\end{array}$ & $\begin{array}{l}\text { Nalini singh } \\
\text { IEEE Journal }\end{array}$ & By applying picture handling edge and edge in view of water shed division. \\
\hline 4 & $\begin{array}{l}\text { Comparative study on methods } \\
\text { used for detection of breast } \\
\text { cancer. }\end{array}$ & $\begin{array}{l}\text { Dr.T. Ramprabha } \\
\text { IEEE Journal }\end{array}$ & $\begin{array}{l}\text { To discuss the basic methods that are involved in the detection of breast cancer, goes } \\
\text { with, 3D plotting, sonogram, mammogram, CT scans etc. }\end{array}$ \\
\hline 5 & $\begin{array}{l}\text { Design and } \\
\text { implementation of contrast } \\
\text { enhancement on mammogram } \\
\text { images for early detection of } \\
\text { breast cancer. }\end{array}$ & $\begin{array}{l}\text { Ranjitha.S } \\
\text { International journal on } \\
\text { research and innovation } \\
\text { Trends Journal }\end{array}$ & $\begin{array}{l}\text { The implementation of FPGA is used to contrast the region of the breast cancer in } \\
\text { the mammogram image and that is used in the detection of cancer. }\end{array}$ \\
\hline 6 & $\begin{array}{l}\text { Wavelet transformation-based } \\
\text { detection of masses in digital } \\
\text { mammograms. }\end{array}$ & $\begin{array}{l}\text { P.Shanmugavadivu } \\
\text { International journal on } \\
\text { research and } \\
\text { innovationJournal }\end{array}$ & $\begin{array}{l}\text { Wave transformation is carried based on the intensity on the mass in the breast with } \\
\text { the mammogram image. }\end{array}$ \\
\hline 7 & $\begin{array}{l}\text { Detection of breast cancer using } \\
\text { ANN. }\end{array}$ & $\begin{array}{l}\text { Sonal Naranje } \\
\text { International journal on } \\
\text { research and } \\
\text { innovationJournal }\end{array}$ & $\begin{array}{l}\text { Artificial neutral network is used ion the detection of the tumor in the breast to } \\
\text { identify the statistical parameters such as entropy, energy, correlation, texture, } \\
\text { standard deviation. }\end{array}$ \\
\hline 8 & $\begin{array}{l}\text { Mammogram image analysis } \\
\text { for breast cancer detection. }\end{array}$ & $\begin{array}{l}\text { A.P.Charate } \\
\text { International journal on } \\
\text { research and } \\
\text { innovationJournal }\end{array}$ & Analysis of the micro calcification or tumor using mammography image. \\
\hline 9 & $\begin{array}{l}\text { Depth segmentation method for } \\
\text { cancer detection in } \\
\text { mammography image. }\end{array}$ & $\begin{array}{l}\text { Parvathy .S. Kumar } \\
\text { International journal on } \\
\text { research and innovation } \\
\text { journal }\end{array}$ & $\begin{array}{l}\text { In a glandular breast the diction could be difficult to identify the lump, which can be } \\
\text { detected using depth segmentation. }\end{array}$ \\
\hline
\end{tabular}




\begin{tabular}{|c|c|c|c|}
\hline & & $\begin{array}{ll}\text { research and } \\
\text { innovationJournal }\end{array}$ & \\
\hline 11 & $\begin{array}{l}\text { Mammography image } \\
\text { enhancement technique for } \\
\text { detecting breast cancer. }\end{array}$ & $\begin{array}{l}\text { Vishwanatha.M } \\
\text { International journal on } \\
\text { research and } \\
\text { innovationJournal }\end{array}$ & $\begin{array}{l}\text { Image enhancement is used to detect the breast cancer using the mammography } \\
\text { image and making it more enhanced and filtering. }\end{array}$ \\
\hline 12 & $\begin{array}{l}\text { Detection of malignant in } \\
\text { digital mammograms from } \\
\text { segmented breast region using } \\
\text { morphological technique. }\end{array}$ & $\begin{array}{l}\text { Prakash Bethapudi } \\
\text { International journal on } \\
\text { research and } \\
\text { innovationjournal }\end{array}$ & $\begin{array}{l}\text { Morphological technique is used to detect the malignant in digital mammogram by } \\
\text { image segmentation. }\end{array}$ \\
\hline 13 & $\begin{array}{l}\text { Mammogram segmentation } \\
\text { using region based methods } \\
\text { with spilt and merge technique. }\end{array}$ & $\begin{array}{l}\text { G.R.Jothilakshmi } \\
\text { International journal of } \\
\text { science and technology }\end{array}$ & $\begin{array}{l}\text { To recognize the kind of growth, division of sore district is essential. To perform } \\
\text { additionally bosom growth order, this paper proposes an enhanced division } \\
\text { calculation utilizingcomputerized mammogram. Technique/Analysis: A mechanized } \\
\text { strategy is utilized to fragment the affected mammogram in a viable way utilizing } \\
\text { split and combining strategy in view of district based division technique by } \\
\text { distinguishing a seed point }\end{array}$ \\
\hline 14 & $\begin{array}{l}\text { Effective detection of mass } \\
\text { abnormality and its } \\
\text { classification using multi- SVM } \\
\text { classification. }\end{array}$ & $\begin{array}{l}\text { G.R.Jothilakshmi } \\
\text { International journal of } \\
\text { science and technology }\end{array}$ & $\begin{array}{l}\text { This paper proposes a strategy for the identification and arrangement of mass } \\
\text { variations from the norm in advanced mammogram pictures utilizing multi SVM } \\
\text { classifier. The objective of this exploration is to build the indicative exactness of } \\
\text { picture preparing and ideal grouping amongst threatening and amiable anomalies in } \\
\text { mass area which lessens the misclassification of bosom pictures. }\end{array}$ \\
\hline 15 & $\begin{array}{l}\text { Identification } \\
\text { microcalcification through its } \\
\text { physical characteristics using } \\
\text { mammogram image. }\end{array}$ & $\begin{array}{l}\text { G.R.Jothilakshmi } \\
\text { International journal of } \\
\text { science and technology }\end{array}$ & Binning the whole image twice with respect to the lesion portion. \\
\hline 16 & $\begin{array}{l}\text { Detection of breast calcification } \\
\text { in digital mammogram using } \\
\text { image processing technique. }\end{array}$ & $\begin{array}{l}\text { N.M.Sangeetha } \\
\text { Journal of Network } \\
\text { communication } \\
\text { emerging technique }\end{array}$ & $\begin{array}{l}\text { A new algorithm is proposed for breast micro calcification, prepare future extraction } \\
\text { and classification. }\end{array}$ \\
\hline 17 & $\begin{array}{l}\text { New Image processing } \\
\text { technique for evaluating breast } \\
\text { micro calcification. }\end{array}$ & $\begin{array}{l}\text { Pricilla Mashado } \\
\text { IEEE Journal }\end{array}$ & New commercial image processing technique (micro pure, tosibha, tustin. \\
\hline 18 & $\begin{array}{l}\text { Detection of micro calcification } \\
\text { in digital mammogram using } \\
\text { one dimensional wavelet } \\
\text { transformation. }\end{array}$ & $\begin{array}{l}\text { T.Balakumar } \\
\text { IEEE journal }\end{array}$ & $\begin{array}{l}\text { By decomposing each line of mammogram by ID wavelet transition into different } \\
\text { frequency sub-band, suppressing the low frequency sub-band contains only high } \\
\text { frequency feature. }\end{array}$ \\
\hline
\end{tabular}

\section{Proposed Methodology}

The input images have been collected from DDSM database which has wide number of mammogram images with and without abnormality. The malignant images with microcalcifications have been considered which is the most dangerous stage of cancer. To recognize such littler microcalcification an equipment gadget is required, which is made by the utilizing the advanced mammography picture from DDSM database the picture of dangerous bosom is familiar. Two levels of binning is completed as for the RoI to figure the scope of reflection coefficient. Direct mapping of reflection coefficient with mass density is anticipated as $3 \mathrm{D}$ and at the same time the extent of first and second level binning are figured to determine the size of the microcalcification .This procedure is then actualized on equipment to make it more commercial for the common people to distinguish the malignancy at a beginning time. The flow chart for the proposed algorithm is shown in Fig. 1 


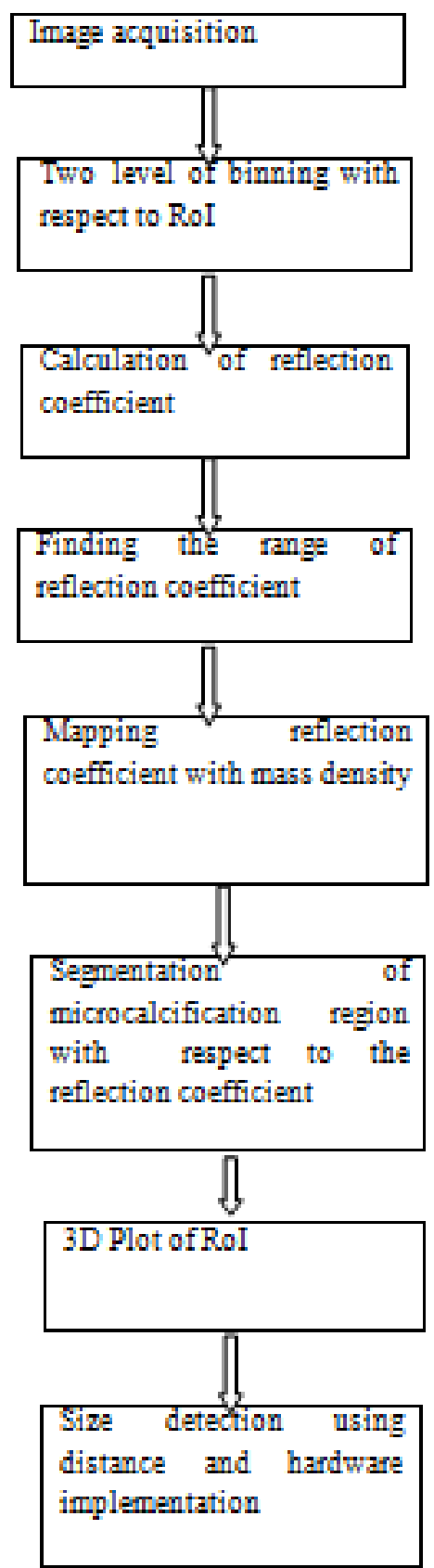

Fig. 1: Flow chart for the proposed methodology

Image Acquisition: Each mammogram image is with size $370 * 237$. These images are collected with some defect or tumor. The place where abnormalities are identified is known as the Region of Interest (ROI) .First stage of any vision system is the image acquisition stage. After the image has been obtained, various methods of processing can be applied to the image to perform the many different vision tasks required today. However, if the image has not been acquired then the proposed tasks may not be achieved, even with the aid of some form of image enhancement (RoI).

Binning of the Image: The image is binned with each block of $370 * 273$ as 12 blocks of 4 rows and 3 columns. For the first level binning $92.5^{*} 91$. So that by binning we have formed an array of matrix in an excel sheet. And the last row and column will be 12 and 9. Basically, consider breaking up your image into distinct (non-overlapping) $\mathrm{M} \times \mathrm{N}$ tiles, where $\mathrm{M}$ and $\mathrm{N}$ are the rows and should be much smaller than the Rows and column of the image. If you consider any grid of $\mathrm{M} \times \mathrm{N}$ pixels; all of these pixels get replaced with a representative color. The way this representative color is calculated is done in many ways... the average is a popular method. The reason why binning is performed is primarily as a data pre-processing technique which is used to reduce the effects of minor observation errors.

Second level binning: This is done at the second level of the matrix where the region of interest is identified with respect to the matrix at which it is present is found. The region where the reflection takes place is defined by the intensity of the crystal. The region with high intensity (255) is considered to be the microcalcification and the value of reflection coefficient to be 1 or nearby. We define return on initial capital investment by making a double veil, which is a parallel picture that is of an indistinguishable size from the picture you need to process. In the veil picture, the pixels that characterize the RoI are set to 1 and every single other pixel set to 0 . In the event that we characterize in excess of one RoI in a picture the areas can be geographic in nature, for example, polygons that envelop adjacent pixels, or characterized by a scope of powers. In the last case, the pixels are not really coterminous. 
Calculation of Reflection coefficient :The region where the reflection takes place is defined by the intensity of the crystal. The region with high intensity is considered to be the microcalcification and the value of reflection coefficient to be 1 or nearby. To detect the reflection coefficient on the 3D graph plotting at $\mathrm{z}$ plane. The proportion of a bundancy of the reflected wave to the occurrence wave, or how much vitality is reflected. On the off chance that the wave has typical frequency, at that point its appearance coefficient can be communicated as: $\mathrm{R}=$ $(\rho 2 \mathrm{~V} 2-\rho 1 \mathrm{~V} 1) /(\rho 2 \mathrm{~V} 2+\rho 1 \mathrm{~V} 1)$ where $\mathrm{R}=$ reflection coefficient, whose esteems run from -1 to $+1 \rho 1=$ thickness of medium 1 .

Finding the range of reflection coefficient: The range of the reflection coefficient is derived considering the intensity of the pixel, which is derived by dividing the value by the highest value of the intensity. Thus by considering the projected graph of the crystal the range of reflection coefficient is derived.

Mapping reflection coefficient with mass density: The range of mass density is found between 2.1 to $3.1 \mathrm{~g} / \mathrm{cm}^{3}$. Linear mapping between the ranges of reflection coefficient to mass density is done to confirm the occurrence of microcalcification. By considering range of reflection coefficient as threshold, the RoI is segmented which is available few bins in second level binning.

3D Plot of RoI: The RoI is projected in 3D and simultaneously the size of the microcalcification in second level binning is done.

Hardware implementation on the Arduino board: This is the latest adjustment of the principal Arduino USB board. It partners with the PC with a standard USB interface and contains the board. It can be connected with a combination of shields: custom young lady sheets with specific features. It resembles the Duemilanove, however has a substitute USB-to-serial chip the ATMega8U2, and as of late arranged naming to make wellsprings of data and yields less requesting to recognize. Remembering the ultimate objective to quicken the expansion technique there is another game plan by using tree structures for the fragmentary things diminishment sort out. There are endless open microcontrollers, DSPs, and field programmable entryway shows (FPGAs), which allows a noteworthy flexibility for dealing with unit executions. By far most of the sensor center points open in the market depend upon 8-bit or 16-bit microcontroller. As per the flow diagram the obtained outputs are shown below.[19 and 20]

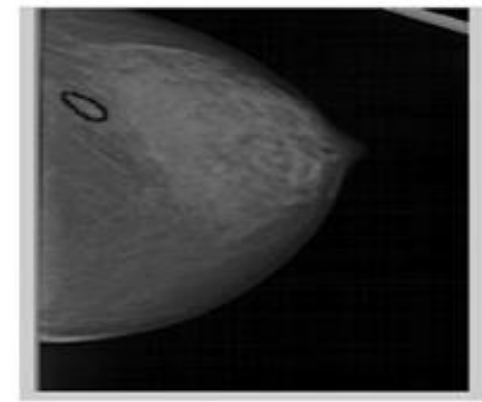

INPUT IMAGE.

Fig. 2: Input image
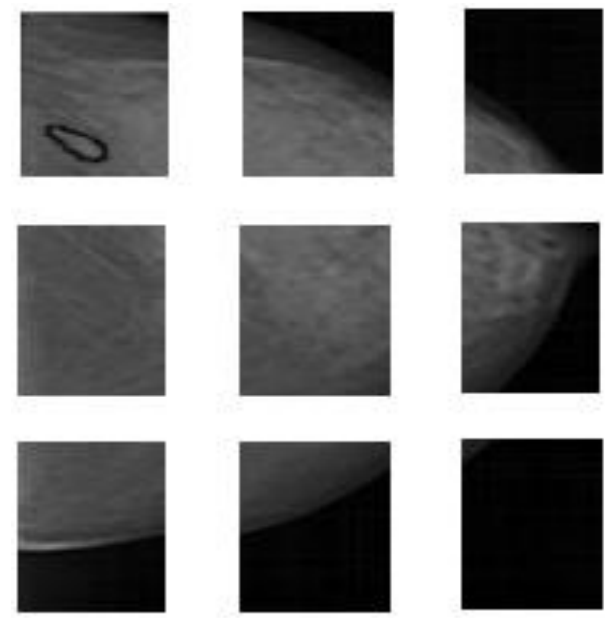

Fig. 3: First level binning-numbering 1 to 9 horizontally

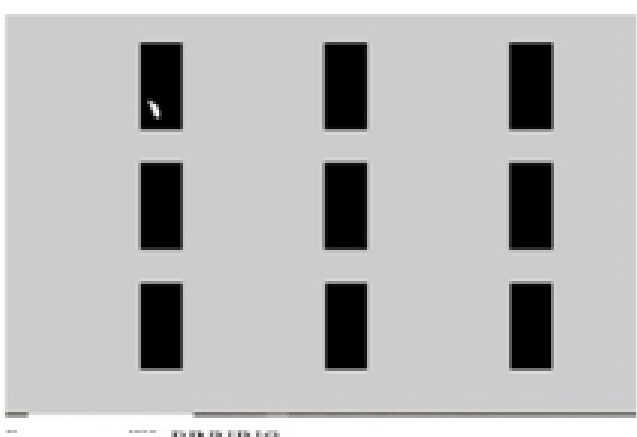

Fig. 4: First level binning with thresholding based on range of reflection coefficient

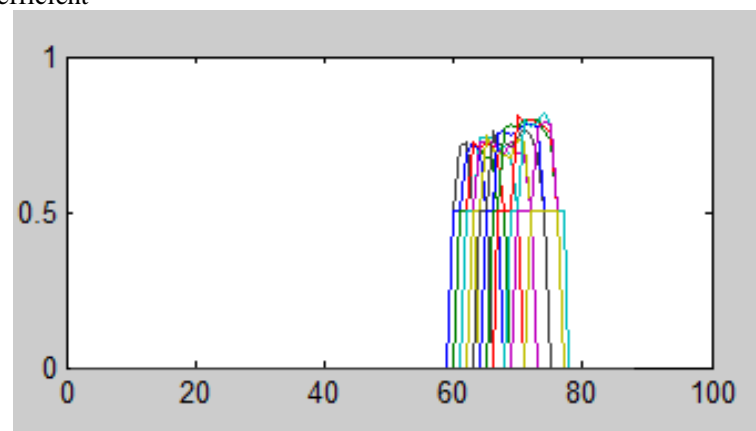

Fig. 5: Graphical representation of reflection coefficient for first bin 1 in first level binning

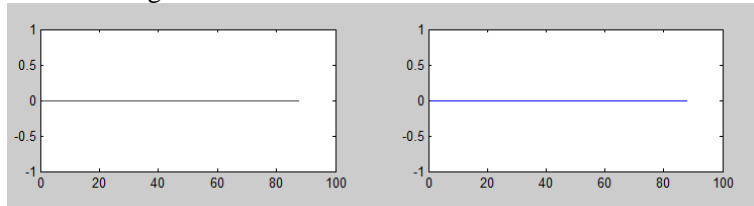

Fig. 6: Graphical representation of reflection coefficient in $2^{\text {nd }}$ and $3^{\text {rd }}$ bin in first level binning

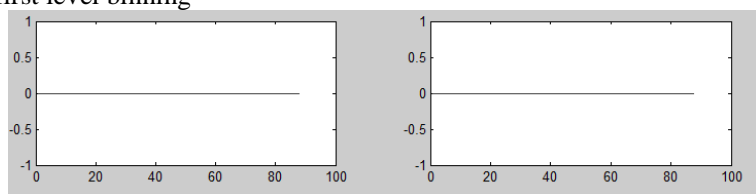

Fig. 7: Graphical representation of reflection coefficient in $4^{\text {th }}$ and $5^{\text {th }}$ bin in first level binning

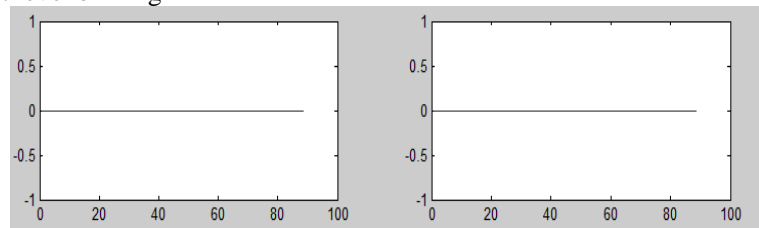

Fig. 8: Graphical representation of reflection coefficient in $7^{\text {th }}$ and $8^{\text {th }}$ bin in first level binning 


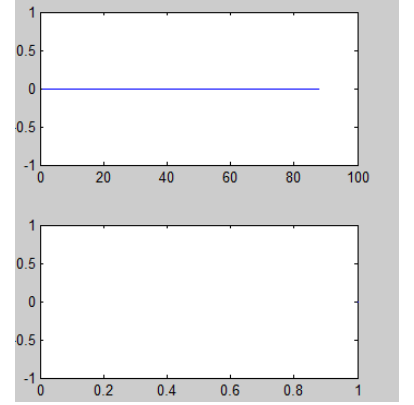

Fig. 9: Graphical representation of reflection coefficient in $9^{\text {th }}$ bin in first level binning
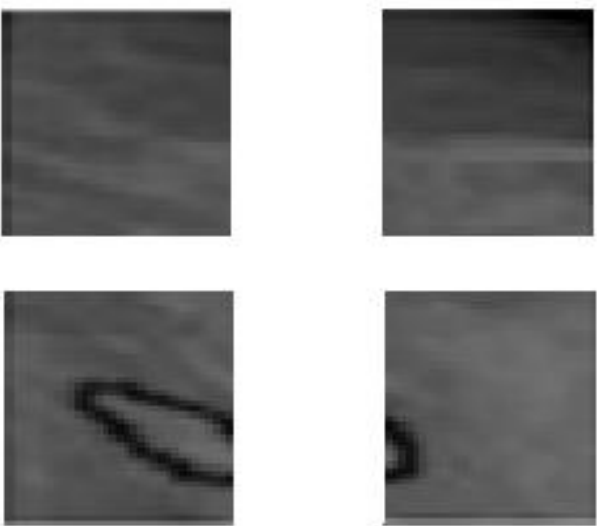

Fig. 10: Second level binning numbering

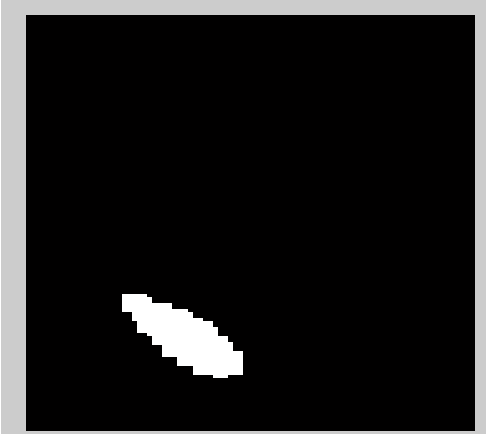

Fig. 11: The Segmented region with microcalcification

\section{Conclusion}

Thus from the literature survey, a lot of detection techniques and various types of methods implemented on the detection of the microcalcification have been analyzed. Basically, Detection of microcalicification is done with the radiologist in which there may be a possibility of high false positive and false negative reports be given. but the detection using image processing technique along with physical characteristics of RoI has never been executed, this effort is quite the idea of making a discovery of a most life threatening disease identified and cured at an early stage. Two levels of binning is completed as for the RoI to ascertain the scope of reflection coefficient. Straight mapping of reflection coefficient with mass density is anticipated as $3 \mathrm{D}$ and at the same time the span of first and second level binning are figured to infer the size of the microcalcification. This procedure is then executed on hardware to make it more commercial for the common people to distinguish the disease at a beginning period.

\section{References}

[1] Kumar PS, Prabhakar P \& Aneesh RP, "Depth Segmentation Method for Cancer Detection in Mammography Images", International Journal on Recent and Innovation Trends in Computing and Communication, Vol.3, No.2, (2015), pp.606-612.
[2] Jothilakshmi GR, "Identification of Micro Calcification through its Physical Characteristics Using Mammogram Images", Journal of Advanced Research in Dynamical and Control Systems, (2017).

[3] Jothilakshmi GR, Sharmila P \& Raaza A, "Mammogram Segmentation using Region based Method with Split and Merge Technique", Indian Journal of Science and Technology, Vol.9, No.40,(2016).

[4] Zhang Y, Tomuro N, Furst J \& Raicu DS, "Image enhancement and edge-based mass segmentation in mammography", International journal on research and innovation trends in computing and communication, (2015).

[5] Balakumaran T, Vennila I \& Gowrishankar C, "Detection of microcalcification in digital mammograms using one dimensional wavelet transform", International Journal of Computer Science and Information Security, (2010), pp.99-104.

[6] Jothilakshmi GR, Christilda RJ, Raaza A, SreenivasaVarma Y \& Rajendran V, "Extracting region of interest using distinct block processing method in sono-mammogram images", International Conference on Computer, Communication and Signal Processing (ICCCSP), (2017), pp.1-7.

[7] Vishwanatha $\mathrm{M}$, "Mammography image enhancement technique for detecting breast cancer", International journal on research and innovation Trends in computing and communication Journal, (2014).

[8] Sangeetha NM, "Detection of breast calcification in digital mammogram using image processing technique", Journal of Network communication emerging technique, (2013).

[9] Charate AP, "Mammogram image analysis for breast cancer detection", International journal on research and innovation Trends in computing and communication, (2015).

[10] Machado P, Eisenbrey JR, Cavanaugh B \& Forsberg F, "New Image Processing Technique for Evaluating Breast Microcalcifications", Journal of Ultrasound in Medicine, Vol.31, No.6,(2012), pp.885-893.

[11] Balakumar T, "Detection of micro calcification in digital mammogram using one dimensional wavelet transformation", IEEE journal, (2014).

[12] Jothilakshmi GR, "Effective detection of mass abnormality and its classification using multi-SVM classification", International journal of science and technology, (2014).

[13] Bethapudi P \& Reddy ES, "Detection of Malignancy in Digital Mammograms from Segmented Breast Region Using Morphological Techniques", IOSR Journal of Electrical and Electronics Engineering (IOSR-JEEE), Vol.5, No.4,(2013), pp.912.

[14] Naranje S, "Detection of breast cancer using ANN", International journal on research and innovation Trends in computing and communication, (2014).

[15] Shanmugavadivu P, Sivakumar V \& Suhanya J, "Wavelet Transformation-Based Detection of Masses in Digital Mammograms", IJRET:International Journal of Research in Engineering and Technology, Vol.3, No.2, (2014), pp.131-138.

[16] Ranjitha S, "Design and FPGA implementation of contrast enhancement on mammogram images for early detection of breast cancer", JRITC, (2014).

[17] Ramprabha T \& Sathya priya T, "A Comparative Study on the Methods Used for the Detection of Breast Cancer", International Journal on Recent and Innovation Trends in Computing and Communication, Vol.5, No.9, (2017), pp.143-147.

[18] Singh N, Mohapatra AG \& Kanungo G, "Breast cancer mass detection in mammograms using $\mathrm{K}$-means and fuzzy C-means clustering", International Journal of Computer Applications, Vol.22, No.2, (2011)

[19] Z Yesembayeva (2018). Features of the legal status of judges: Kazakhstan experience and foreign realities Opción, Año 33. 447474

[20] A Mukanbetkaliyev, S Amandykova, Y Zhambayev, Z Duskaziyeva, A Alimbetova (2018). The aspects of legal regulation on staffing of procuratorial authorities of the Russian Federation and the Republic of Kazakhstan Opción, Año 33. 187-216 